\title{
LEI 12.318/08/10: INSTRUMENTO DE PROTEÇÃO DE DIREITOS DA CRIANÇA OU ADOLESCENTE FRENTE AOS PERIGOS DA ALIENAÇÃO PARENTAL
}

\section{Gabriela Cristina da Silva'}

Resumo: O trabalho faz uma análise acerca dos efeitos causados pela síndrome de alienação parental (diagnosticada e estudada pelo psiquiatra norte-americano Richard Gardner) prevista na Lei 12.318/10 e nas decisões exaradas pelo Poder Judiciário Brasileiro. Trazendo seu conceito, sua identificação, suas consequências e sua diferenciação de alienação parental. Ressalta a importância de sua tipificação no ordenamento jurídico. Mostrando, também, a evolução da família seus limites e definição moderna, esclarecendo a importância da tipificação da síndrome. Este artigo é o resultado de uma pesquisa sobre os efeitos da síndrome de alienação parental no Poder Judiciário Brasileiro após a promulgação da Lei 12.318/10.

Palavras-chave: Síndrome de Alienação Parental. Alienação parental. Família. Richard Gardner. Sap. Tipificação.

\section{INTRODUÇÃO}

Este artigo tem por finalidade fazer uma análise da Síndrome da Alienação Parental. O ponto inicial é conceituar

1 Pós-graduanda em Direito Público pela Fundação Universidade de Blumenau. Bacharela no curso de Direito pela Universidade do Vale do Itajaí (UNIVALI) e aluna do Módulo II da Escola Superior da Magistratura do Estado de Santa Catarina (ESMESC). E-mail: gabrielanbs@gmail.com.br 
família, fazendo um estudo sobre a evolução deste instituto. Introduz a diferenciação de Síndrome da Alienação parental e Alienação Parental, seguindo em hipóteses da reversão do quadro e o papel do Poder Judiciário. Apontam-se soluções ponderáveis e traz a baila uma breve explanação sobre Lei $n^{\circ}$ 12.318 de 26 de agosto de 2010.

A Síndrome da Alienação Parental, diferente da Alienação Parental, é temática amplamente tratada em países desenvolvidos. Os Estados Unidos, inclusive codifica penalmente as conseqüências da Síndrome da Alienação Parental. No Brasil, recentemente, a síndrome passou a fazer parte da legislação pátria, todavia poucos juízes, promotores e advogados já a traziam à pauta.

Entendida, para muitos, como a "lavagem cerebral" da criança contra um dos progenitores. A Síndrome da Alienação Parental é situação que indiscutivelmente trará problemas a todos os envolvidos, especialmente para o infante/adolescente. Que sofrerá turbações em sua personalidade, já que os atores em cena são os que mais lhe deveriam prestar assistência e segurança.

Objetiva-se, desta maneira, explanar acerca do tema, o qual é de suma importância. Uma vez que, a matéria superou as vias de codificação no Brasil, apesar de que, pela dimensão do problema, já deveria a muito estar desenvolvendo sua práxis para fim de pacificação.

\section{A SÍNDROME DA ALINEÇÃO PARENTAL E O PODER JUDICIÁRIO}

\subsection{Aportes Históricos}

O objeto da presente pesquisa é a "síndrome da alienação parental”, portanto cabe situá-lo no espectro do ordenamento jurídico brasileiro: o direito de família, que pode ser definido como o ramo do direito que contém normas jurídicas relacio- 
nadas com a estrutura, organização e proteção da família. Ramo que trata das relações familiares e das obrigações decorrentes dessas relações. ${ }^{2}$

Destacam-se, nesse sentido, que a família, em todos os seus aspectos, sofreu grandes modificações ao longo do tempo, sendo assim, para um melhor entendimento, se faz necessário identificar o conceito de família.

Ora significa o conjunto das pessoas que descendem de tronco ancestral comum, tanto quanto essa ascendência se conserva na memória dos descendentes, ou nos arquivos, ou na memória dos estranhos. Ora o conjunto de pessoas ligadas a alguém, ou a um casal, pelos laços de consangüinidade ou de parentesco civil; ora o conjunto das mesmas pessoas, mais os afins apontados por lei; ora o marido e a mulher, descendentes e adotados; ora, finalmente, marido, mulher e parentes sucessíveis de um e de outra. ${ }^{3}$

No que tange a Síndrome da Alienação Parental, ressaltase que apresentou maiores considerações em meados dos anos 80 , quando foi descoberto pelo professor de psiquiatria infantil da Universidade de Columbia (EUA) Richard Gadner.

Constatou-se que as crianças que passavam por processos de disputas judiciais entre seus pais apresentavam uma forte rejeição por um deles. Desta percepção, originou-se a especificação: Síndrome da Alienação Parental (SAP).

Ato contínuo, outras síndromes tiveram ligações com causas de situações de litígio conjugal. Cita-se como exemplo, em 1986, a síndrome das alegações sexuais (SAID) nomeado por Blush e Roos, pelas falsas acusações de abuso sexual que o genitor alienado era acusado.

No tocante ao cenário internacional, os países desenvolvidos como: Estados Unidos, Canadá, Reino Unido, entre outros, perceberam que a Síndrome de Alienação Parental

2 DIREITO DE FAMÍLIA. Enciclopédia eletrônica. Disponível em HTTP://pt. wikipedia. org/wiki/Direito de fam\%C3\%ADila. Acesso: 03.04.2011.

3 RIZZARDO, Arnaldo. Direito de Família: Lei n 10.406, de 10.01.2002. p. 11. 
tornou-se uma epidemia. Como também a Síndrome de Medéia, em 1988, descrita por Jacoobs como a forma da mãe acabar com a relação dos filhos com o pai transferindo todas as suas frustrações do abandono por ela sentidas ao filho.

Notando que, no Brasil, o assunto surgiu principalmente por meio de associações de pais separados, acompanhouse mensalmente a atualização dos sites dessas associações em buscas por novas informações sobre a difusão do tema SAP. Além disso, com o recebimento da mala direta do Boletim Eletrônico do Instituto de Direito de Família (IBDFAM), que tem número variado de edições a cada mês, e por meio da participação em correio eletrônico para grupos de Associação de pais e mães separadas (APASE) foi possível acompanhar a divulgação de sites, vistas com profissionais, matérias em jornais e revistas, reportagens, bem como a realização de eventos sobre o tema SAP. Atualmente, parte dessa divulgação encontra-se organizada em um site brasileiro exclusivamente para o tema. ${ }^{4}$

Baseando-se nos históricos locais, mas precisamente na Capital do Estado de Santa Catarina, é mencionado como essencial na divulgação da guarda compartilhada e alienação parental, a sociedade civil denominada Apase. Veja-se:

No Brasil a Apase tem sido um dos principais meios de divulgação do assunto. Constituída como sociedade civil sem fins lucrativos em 1997, na cidade de Florianópolis, a Apase assegura que fundamentalmente seus ideias na Constituição Federal e no Estatuto da Criança e do Adolescente. Nos últimos anos, atuou ativamente para a criação de lei sobre a guarda compartilhada, a qual foi sancionada em 13 de junho de 2008 pelo Presidente da República. EM fins do mesmo ano, após a entrada em vigor desta lei, a Apase juntamente com alguns profissionais que atuam no judiciário voltara-se para a elaboração de um novo anteprojeto de lei, agora tendo como alvo o que chama de alienação parental. ${ }^{5}$

4 SOUZA, Analícia Martins de. Síndrome de Alienação Parental - um novo tema nos juízos de família. Cortez Editora. $1^{\mathrm{a}}$ ed. São Paulo, 2010.

5 Ibid., p.93. 
Neste vértice, Mônica Guazelli ${ }^{6}$ esclarece:

[...] que a constatação da existência deste tipo de síndrome aconteceu no final dos anos 80, nos Estados unidos por Richard Gardner, psiquiatra infantil da Universidade de Columbia, o qual é a maior referência do assunto. Contudo, importante salientar que síndrome ou equivalente também foi identificada mais ou menos na mesma época, por vários outros psiquiatras e psicólogos norte-americanos que trabalhavam com crianças e famílias pós-divórcio. ${ }^{7}$

Em suma, demonstrou-se o ciclo histórico da síndrome da alienação parental.

\section{DA SÍNDROME DA ALIENAÇÃO PARENTAL}

Com a separação do casal e a inevitável atribuição da guarda do filho comum a um dos genitores, restará ao outro, a convivência, na qual se visa minimizar os efeitos causados com o fim da sociedade conjugal. É uma forma de preservar os laços de convivência entre ambos. Abre-se, então, a possibilidade ao genitor não guardião de participar da criação e da formação da criança.

6 Ibid.,p.141.

7 GUAZELLI, Mônica. Litígio de Família: Quem protege as crianças?. IBDEFAM, 2004, coordenação: Maria Regina Fay de Azambuja, Maritana Viana da Silveira e Denise Duarte Bruno, 'Infância em Família: um compromisso de todos', p. $167 / 175$. 
e buscarem o genuíno interesse dos filhos - não há espaço para egoísmos ou narcisismos, nem para animosidades freqüentes mas de pequena monta, que só prejudicam o entendimento e fomentam a discórdia". ${ }^{8}$

Determinado em acordo ou estipulado pelo juiz, o conhecido Direito de Visitas (vale lembrar que, antes da Carta Magna de 1.988 o termo era utilizado era Visitas, mas hoje o correto é o Direito de Convivência).

Neste vértice, no caso de síndrome de alienação parental vislumbra-se que a guarda e visitação de filhos envolvem conflitos graves. $\mathrm{O}$ guardião alienador busca incutir no filho que seu não guardião é pessoa repudiável. Impede a visitação mesmo em dias determinados judicialmente, faz falsas acusações, muitas vezes gravíssimas, de abuso sexual, impede contatos telefônicos entre o filho e o guardião, enfim, denigre a imagem da outra parte sem qualquer embasamento, que não sua vingança. Firmase nesse momento, o sentimento de abandono, de rejeição, de desequilíbrio da criança e, relação a seu pai, não raro inocente, que não consegue exercer a paternidade em plenitude. ${ }^{9}$

Vale transcrever:

As conseqüências quanto à formação da criança e a suposta criação de traumas geram problemas futuros a esse indivíduo. "As conseqüências podem ser gravíssimas, uma vez que a criança alimente a idéia de que é fruto de um genitor cruel, ruim, que a abandonou etc.”. Além disso, Mesquita afirmou que esses traumas trazem doenças sérias como, Síndrome do Pânico, TOC ou até mesmo desvios de caráter que não estão descartados como conseqüências possíveis de um cenário como este. "Sempre existirá a figura de uma ex-mulher ou ex-marido e, quando há filhos envolvidos, a

8 SILVA, Denise Maria Perissini da. Guarda compartilhada e síndrome da alienação parental. Autores Associados LTDA: São Paulo, 2010. p. 2.

9 AMARAL, Sylvia Maria Mendonça do. Alienação parental: nova lei $x$ sentimentos. Revista Jurídica Consulex, Brasilia , v.13, n.309, p. 12, nov.2009. 
de um pai ou uma mãe e não a de um EX-pai ou EX-mãe”, disse.

Mesquita ainda fala que manter esses vínculos saudáveis é absolutamente necessário para não agravar ainda mais a angústia e o sofrimento já existentes em um cenário de separação. "Não me parece que seja a existência de uma lei que irá garantir isso, ao invés da consciência de todas as pessoas envolvidas em optarem por atitudes, posturas e ações norteadas ao bem estar de todos e notoriamente de suas crianças.", finalizou. ${ }^{10}$

A síndrome da alienação parental trata-se de um processo patológico, como anteriormente destacado, foi identificado pelo Professor de Psiquiatria Infantil da Universidade de Columbia (EUA), Richard Gardner, em 1985, e que envolve três estágios: leve, médio e grave.

No primeiro estágio, a criança apresenta apego excessivo ao genitor alienante, afastando-se do genitor alienado. No seguinte (médio), a vítima pode cooperar para desmoralizar o alienado, mas, sem dúvida a alienação atinge o seu ápice quando ocorrem tragédias como o assassinato de um dos genitores pelo outro, do (s) filho (s) e até mesmo suicídio.

Inúmeras são as formas de se levar a cabo a alienação parental, sobretudo mediante "lavagem cerebral". Entretanto, é possível reconhecê-la de pronto no comportamento do genitor que denigre a imagem do outro; apresenta o(a) companheiro (a) à criança como seu "novo" pai ou mãe; faz comentários desagradáveis sobre presentes, obriga a criança a optar por um dos pais; externa seu desagrado diante as manifestações de carinho para com o outro; emite falsas acusações de abuso sexual, podendo ocorrer aqui a "implantação de falsas memórias", onde a criança é levada a creditar em fatos inverídicos. ${ }^{11}$

10 http://andreadecastro.wordpress.com/page/4/. Acessado em 03.04.2011.

11 DIAS, Arlene Mara de Sousa. Alienação parental e o papel do Judiciário. Revista Jurídica Consulex. Brasília, v.14, n.321, p. 46-47, jun.2010. 


\subsection{Diferença de Síndrome Alienação Parental e Alienação Parental}

Embora intimamente ligadas, uma e o complemento da outra e seus conceitos não podem se confundir.

Alienação Parental é a desconstituição da figura parental de um dos genitores ante a criança. É uma campanha de desmoralização, de marginalização desse genitor. Manipulada com o intuito de transformar esse genitor num estranho, a criança então é motivada a afastá-lo do seu convívio. Esse processo é praticado dolosamente ou não por um agente externo, um terceiro e, não esta restrito ao guardião da criança. Há casos em que a Alienação Parental é promovida pelos Avôs, por exemplo, sendo perfeitamente possível que qualquer pessoa com relação parental com a criança ou não, a fomente.

A Síndrome de Alienação Parental diz respeito aos efeitos emocionais e as condutas comportamentais desencadeados na criança que é ou foi vítima desse processo. Grosso modo, são as seqüelas deixadas pela Alienação Parental.

\section{REVERSÃO DO QUADRO E O PAPEL DO PODER JUDICIÁRIO}

A possibilidade de reversão do quadro, para que se restabeleça a relação prejudicada, deve seguir, segundo estudos, 06 (seis) fases ${ }^{12}$ :

A primeira delas consiste da criança já em uma causa de transição, sem qualquer contato com o alienador e restabelecendo o contato com o genitor alienado, através de visitas longas em aumento em gradação e freqüentas, conforme forem ambos se adaptando. A segunda fase implica que, após as visitas mais duradouras, a criança considere viver ali por definitivo com o alienado, sem convívio com o alienador. Na terceira fase, a criança passa a viver com o genitor alienado, ainda sem

12 www.unicap.br/.../06/Qual-a-contribuição-da-TF-na-Síndrome-da-alienação-Parental1.doc. Acesso em 02/04/2011. 
o mínimo contato com o genitor alienado, e na tentativa de contato, desse, se houver, deverá ser punida. Na quarta fase, há o contato telefônico do alienador com a criança, na condição de que o intuito seja não possibilitar a manipulação e sim o seu controle. $\mathrm{Na}$ fase quinta, a visita entre o alienador e o filho é na casa do alienado, sob vigilância, controlando a animosidade; Por fim, na última fase, se restabelecendo o alienador, volta a possuir o direito de visitas ao filho na casa do alienador, a princípio sob acompanhamento e controladas.

Desta forma, o seguimento das fases de restituição devem ser seguidas, uma vez que enquanto não se instala a Síndrome, é possível a reversão da Alienação Parental (com ajuda de terapia e do Poder Judiciário) e o restabelecimento do convívio com o Genitor Alienado. Porém, quando a Síndrome se instala, sua reversão ocorre em pouquíssimos casos e já na infância.

\subsection{Soluções Ponderáveis}

De toda a situação recolhida pela SAP, à melhor maneira de se evitar a problemática, em divórcio litigioso em que a guarda entre em disputa, seria a colocação da criança na guarda do genitor que melhor apresente condições, sob vários aspectos. Nesse sentido, colhe-se do Tribunal de Santa Catarina:

Esse tema começa a despertar a atenção, pois é prática que vem sendo utilizada de forma recorrente e irresponsável. Muitas vezes, quando da ruptura da vida conjugal, um dos cônjuges não consegue elaborar adequadamente o luto da separação e o sentimento de rejeição, de traição, o que faz surgir um desejo de vingança: desencadeia um processo de destruição, de desmoralização, de descrédito do ex-parceiro. O filho é utilizado como instrumento de agressividade - é induzido a odiar o outro genitor. Trata-se de verdadeira campanha de desmoralização. A criança é induzida a afastar-se de quem ama e de quem também a ama. Isso gera contradição de sentimentos e destruição do vínculo 
entre ambos. Restando órfão do genitor alienado, acaba se identificando com o genitor patológico, passando a aceitar como verdadeiro tudo o que lhe é informado. ${ }^{13}$

Outra maneira de se evitar qualquer problema para a criança, com relação à guarda, seria optar pela guarda compartilhada, desde que haja a lealdade nos procedimentos dos cônjuges:

Tais condições não pretendem desestimular os esforços da doutrina e da jurisprudência para o estabelecimento de uma co-responsabilidade, sempre que possível, da guarda. O estudo da guarda compartilhada faz-se relevante e deve ser intensificado, À medida que contribui à recuperação de uma apreciação ética das relações de filiação, de modo absolutamente necessário e complementar ao exercício conjunto da autoridade parental..$^{14}$

A disputa de guarda leva à carga da própria separação, sendo o maior prejudicado o menor envolvido, que inclusive, como vimos na Síndrome em estudo, é vítima.

Destarte, com apresentação da melhor resposta ao problema, que deverá sempre ser revisto em consonância com o caso concreto e principalmente, com a evolução familiar no tempo.

\section{LEI N 12.318 DE 26 DE AGOSTO DE 2010}

A lei 12.318/2010 inicia sua abordagem conceituando alienação parental no seu art. $2^{\circ}$ e, ainda, determina os sujeitos legitimados a interferir quando constatado a ocorrência de tal instituto, no parágrafo único contempla um rol exemplificativo de condutas configuradoras de alienação parental.

13 Santa Catarina. Tribunal de Justiça do Estado de Santa Catarina. Agravo de Instrumento $n^{\circ}$. Relator: Nelson Schaefer Martins. Data de Julgamento: 11.01.2011.

14 TEPEDINO, Gustavo. Instituto Brasileiro de Direito de Família. A Disciplina da guarda e da autoridade parental na ordem. VI Congresso Brasileiro de Direito de Família. Belo Horizonte: Del Rey,2004. 
Doravante, no art.3, enuncia que o ato de alienação parental fere o direito fundamental à convivência familiar, garantia que se encontra prevista no Art. 226 da Constituição Federal, bem como no Art. 19 do Estatuto da Criança e do Adolescente. Neste vértice, aduz que a alienação parental prejudica a realização de afeto nas relações com os pais ou o grupo familiar. A afetividade é hoje valor considerado integrante da idéia de família saudável.

Além da definição do ato de alienação parental, dos sujeitos envolvidos em sua prática e dos direitos fundamentais eventualmente violados, a Lei 12.318/10 trouxe regras sobre a instrumentalização processual do instituto, nos artigos $4^{\circ}$ e $5^{\circ}$.

Além das determinações possiveis a partir do reconhecimento processual do ato de alienação parental, por meio de seu Art. $8^{\circ}$, determina que a alteração de domicílio da criança ou adolescente é irrelevante para a determinação da competência relacionada às ações fundadas em direito de convivência familiar. Salvo se decorrente de consenso entre os genitores ou de decisão judicial.

$\mathrm{O}$ ato normativo foi parcialmente vetado, através da mensagem de veto $\mathrm{n}^{\circ} 513$, por contrariedade ao interesse público.

Todavia, verificado ato de alienação parental a partir de 27 de agosto de 2010, poderá haver a provocação da jurisdição para que se aplique o regramento disposto na Lei 12.318/10 até mesmo para os processos em curso, com eventual provocação incidente.

Denota-se que a legislação traz ordenamentos jurídicos que visam a proteger os filhos de reações repudiáveis de pais, os quais, por problemas próprios e/ou resultantes de términos de relacionamentos, trazem em seus atos a prática da alienação parental. No decorrer da aplicação do embasamento jurídico, será adequada necessidade à espécie, criando subsídios e estrutura para aplicar o teor da legislação, com o escopo de proteger o filho, resguardar o direito do alienado e punir o alienador. 


\section{CONCLUSÃO}

Ao findar o presente artigo, alcança-se o objetivo proposto, que se consolidou de modo paulatino, a partir da estratégica linha de pesquisa traçada, na qual o enredo foi desmantelado e, de maneira didática, apresentado.

Conclui-se que, a Síndrome Alienação Parental é situação decorrente de relações desarmonizadas, nas quais a prole é utilizada para satisfações egoístas e pessoais do progenitor alienador, que busca cortar o vínculo do filho com o outro genitor como "castigo". Para a empreitada, o pai/mãe alienador começa a "mimar" o filho com falsas informações e memórias do pai/mãe alienado (a), que por sua vez, de maneira gradativa, vai perdendo o contato com o infante/adolescente, até o total afastamento.

$\mathrm{O}$ que se discute é a proteção aos direitos e garantias fundamentais das crianças e adolescentes, inclusive de preceito constitucional. O Artigo 227 'caput' da Constituição dispõe ser dever da família, da sociedade e do Estado assegurar à criança e ao adolescente, com absoluta prioridade, o direito a convivência familiar. Ora se é dever, o genitor que fomenta a SAP esta violando um dever, uma determinação constitucional do próprio filho, o que e absolutamente inconcebível.

Configura negligência quando o genitor guardião obstrui o direito da criança do convívio com o outro genitor e, portanto, passível de punição. Num estado adiantado acaba por transformar a criança órfã de um genitor vivo, por dano ou abuso psicológico e emocional, muitas vezes irreversível, que pode desencadear uma serie de distúrbios na vida da criança.

Em que pese a Síndrome da Alienação Parental ter sido estudada e exortada na década 1980, sua existência é muito anterior. Em países subdesenvolvidos, a situação ainda não se encontra legalizada, assim como suas penalizações e conseqüente perda do poder familiar. Atualmente, a Lei no 12.318/2010, que faz permissivo legal, ordena o tema. 
Com a nova legislação e na sua aplicação, a reversão do quadro da Síndrome de Alienação Parental terá inúmeras deficiências, haja vista, o despreparo dos profissionais colaboradores do sistema. Mesmo assim, o avanço é significativo, visto que o problema é reconhecido e assim premiado por legislação própria.

Estima-se que os julgados do Poder Judiciário sejam aperfeiçoados. E na sua amplitude, criem alicerces sólidos, evitando que a prole, dentro de sua habitual inocência, tenha de conviver com atos maldosos de seus pais, que por egoísmo e despreparo traz sérios prejuízos de ordem moral, psicológica e física aos seus filhos.

Concluo este artigo, perplexa com o tema principal, ciente de que neste exato momento várias crianças estão sendo vítimas de atos do alienador. E que, da mesma forma, há um alienado sofrendo por alegações inexistentes s inverídicas, lutando para provar a verdade e libertar sua prole de atos errôneas oriundos geralmente do término de uma relação mal resolvida.

Abstract: This paper does an analysis about the effects caused by the Parental Alienation Syndrome (diagnosed and studied by the American psychiatrist Richard Gardner) on the decisions made by the Brazilian Judiciary legal system. Its concept, identification and its consequences, and the difference of parental alienation. It also highlights the importance of its typification on the Legal department. Showing also the family's evolution and its limits and modern definition, clearing up the importance of the syndrome typification. This article is the result of a parental alienation syndrome effect research on the Brazilian Judiciary legal system.

Keywords: Parental Alienation Syndrome. Parental Alienation. Family. Richard Gardner. SAP. Typification. 


\section{REFERÊNCIAS}

AMARAL, Sylvia Maria Mendonça do. Alienação parental: nova lei x sentimentos. Revista Jurídica Consulex. Brasília, v.13, n.309, p. 12, nov.2009.

APASE. Associação de Paes e Mães Separados: www.apase.org.br. Acesso em 02.3.2011.

DIAS, Arlene Mara de Sousa. Alienação parental e o papel do Judiciário. Revista Jurídica Consulex. Brasília, v.14, n.321, p. 46-47, jun.2010.

DIREITO DE FAMÍLIA. Enciclopédia eletrônica. Disponível em HTTP:// pt.wikipedia.org/wiki/Direito_de_fam\%C3\%ADila. Acesso: 03.04.2011.

GUAZELLI, Mônica. Litígio de Família: Quem protege as crianças?.

IBDEFAM, 2004, coordenação: Maria Regina Fay de Azambuja, Maritana Viana da Silveira e Denise Duarte Bruno, 'Infância em Família: um compromisso de todos', p. 167/175.

http://andreadecastro.wordpress.com/page/4/. Acessado em 03.04.2011. http://www.unicap.br/.../06/Qual-a-contribuição-da-TF-na-Síndrome-daalienação-Parental1.doc. Acesso em 02/04/2011.

RIZZARDO, Arnaldo. Direito de Família: Lei no 10.406, de 10.01.2002.

SILVA, Denise Maria Perissini da. Guarda Compartilhada e Síndrome da Alienação Parental. Autores Associados LTDA: São Paulo, 2010.

SOUZA, Analícia Martins de. Síndrome de Alienação Parental - um novo tema nos juizos de família. Cortez Editora. $1^{\text {a }}$ ed. São Paulo, 2010.

TEPEDINO, Gustavo. Instituto Brasileiro de Direito de Família. A Disciplina da guarda e da autoridade parental na ordem. VI Congresso Brasileiro de Direito de Família. Belo Horizonte; Del Rey, 2004.

Tribunal de Justiça de Santa Catarina. Agravo de Instrumento no 2010.044042-5. Relator: Nelson Schaefer Martins. Data de Julgamento: 11.01.2011. 


\section{ANEXO}

O PRESIDENTE DA REPÚBLICA Faço saber que o Congresso Nacional decreta e eu sanciono a seguinte Lei:

Art. 1ำ Esta Lei dispõe sobre a alienação parental.

Art. 2o Considera-se ato de alienação parental a interferência na formação psicológica da criança ou do adolescente promovida ou induzida por um dos genitores, pelos avós ou pelos que tenham a criança ou adolescente sob a sua autoridade, guarda ou vigilância para que repudie genitor ou que cause prejuízo ao estabelecimento ou à manutenção de vínculos com este.

Parágrafo único. São formas exemplificativas de alienação parental, além dos atos assim declarados pelo juiz ou constatados por perícia, praticados diretamente ou com auxílio de terceiros:

I - realizar campanha de desqualificação da conduta do genitor no exercício da paternidade ou maternidade;

II - dificultar o exercício da autoridade parental;

III - dificultar contato de criança ou adolescente com genitor;

IV - dificultar o exercício do direito regulamentado de convivência familiar;

$\mathrm{V}$ - omitir deliberadamente a genitor informações pessoais relevantes sobre a criança ou adolescente, inclusive escolares, médicas e alterações de endereço;

VI - apresentar falsa denúncia contra genitor, contra familiares deste ou contra avós, para obstar ou dificultar a convivência deles com a criança ou adolescente;

VII - mudar o domicílio para local distante, sem justificativa, visando a dificultar a convivência da criança ou adolescente com o outro genitor, com familiares deste ou com avós.

Art. 3o- A prática de ato de alienação parental fere direito fundamental da criança ou do adolescente de convivência fami- 
liar saudável, prejudica a realização de afeto nas relações com genitor e com o grupo familiar, constitui abuso moral contra a criança ou o adolescente e descumprimento dos deveres inerentes à autoridade parental ou decorrentes de tutela ou guarda.

Art. 4o Declarado indício de ato de alienação parental, a requerimento ou de ofício, em qualquer momento processual, em ação autônoma ou incidentalmente, o processo terá tramitação prioritária, e o juiz determinará, com urgência, ouvido o Ministério Público, as medidas provisórias necessárias para preservação da integridade psicológica da criança ou do adolescente, inclusive para assegurar sua convivência com genitor ou viabilizar a efetiva reaproximação entre ambos, se for o caso.

Parágrafo único. Assegurar-se-á à criança ou adolescente e ao genitor garantia mínima de visitação assistida, ressalvados os casos em que há iminente risco de prejuízo à integridade física ou psicológica da criança ou do adolescente, atestado por profissional eventualmente designado pelo juiz para acompanhamento das visitas.

Art. 5 Havendo indício da prática de ato de alienação parental, em ação autônoma ou incidental, o juiz, se necessário, determinará perícia psicológica ou biopsicossocial.

$\S 1^{\circ}$ O laudo pericial terá base em ampla avaliação psicológica ou biopsicossocial, conforme o caso, compreendendo, inclusive, entrevista pessoal com as partes, exame de documentos dos autos, histórico do relacionamento do casal e da separação, cronologia de incidentes, avaliação da personalidade dos envolvidos e exame da forma como a criança ou adolescente se manifesta acerca de eventual acusação contra genitor.

$\S 2$ A perícia será realizada por profissional ou equipe multidisciplinar habilitados, exigido, em qualquer caso, aptidão comprovada por histórico profissional ou acadêmico para diagnosticar atos de alienação parental. 
§ 3ㅇ perito ou equipe multidisciplinar designada para verificar a ocorrência de alienação parental terá prazo de 90 (noventa) dias para apresentação do laudo, prorrogável exclusivamente por autorização judicial baseada em justificativa circunstanciada.

Art. 6- Caracterizados atos típicos de alienação parental ou qualquer conduta que dificulte a convivência de criança ou adolescente com genitor, em ação autônoma ou incidental, o juiz poderá, cumulativamente ou não, sem prejuízo da decorrente responsabilidade civil ou criminal e da ampla utilização de instrumentos processuais aptos a inibir ou atenuar seus efeitos, segundo a gravidade do caso:

I - declarar a ocorrência de alienação parental e advertir o alienador;

II - ampliar o regime de convivência familiar em favor do genitor alienado;

III - estipular multa ao alienador;

IV - determinar acompanhamento psicológico e/ou biopsicossocial;

$\mathrm{V}$ - determinar a alteração da guarda para guarda compartilhada ou sua inversão;

VI - determinar a fixação cautelar do domicílio da criança ou adolescente;

VII - declarar a suspensão da autoridade parental.

Parágrafo único. Caracterizado mudança abusiva de endereço, inviabilização ou obstrução à convivência familiar, o juiz também poderá inverter a obrigação de levar para ou retirar a criança ou adolescente da residência do genitor, por ocasião das alternâncias dos períodos de convivência familiar.

Art. 7ํ A atribuição ou alteração da guarda dar-se-á por preferência ao genitor que viabiliza a efetiva convivência da criança ou adolescente com o outro genitor nas hipóteses em que seja inviável a guarda compartilhada. 
Art. 8o A alteração de domicílio da criança ou adolescente é irrelevante para a determinação da competência relacionada às ações fundadas em direito de convivência familiar, salvo se decorrente de consenso entre os genitores ou de decisão judicial.

Art. 9o (VETADO)

Art. 10. (VETADO)

Art. 11. Esta Lei entra em vigor na data de sua publicação.

Brasilia, 26 de agosto de 2010; 189ㅇa Independência e 122 da República.

LUIZ INÁCIO LULA DASILVA 